\title{
Educação em saúde para crianças: estratégia de combate a dengue
}

\author{
Health education for children: strategy to combat dengue \\ Educación en salud para niños: estrategia de lucha contra el dengue
}

Recebido: 15/12/2020 | Revisado: 23/12/2020 | Aceito: 27/12/2020 | Publicado: 02/01/2021

Geraldo Junio Abreu

ORCID: https://orcid.org/0000-0002-6617-5941 Faculdade de Minas, Brasil

E-mail: gj.abreu@hotmail.com

Carla Maria Queiroz

ORCID: https://orcid.org/0000-0001-9921-5084

Faculdade de Minas, Brasil

E-mail: carlamariaqueiroz@gmail.com

Fabiane Vieira Soares

ORCID: https://orcid.org/0000-0001-9510-9399

Faculdade de Minas, Brasil

E-mail: fabianevisoa@hotmail.com

Israel Lucas dos Santos Fernandes

ORCID: https://orcid.org/0000-0002-2656-9778

Faculdade de Minas, Brasil

E-mail: israel.lucas.santos.fernandes@gmail.com

Natália Alves de Carvalho

ORCID: https://orcid.org/0000-0002-7732-5298

Faculdade de Minas, Brasil

E-mail: nataliaalves.c@hotmail.com

Brenda Linique Sousa da Cruz

ORCID: https://orcid.org/0000-0002-1946-1144 Faculdade de Minas, Brasil

E-mail: brendalinequey2017@gmail.com

Janyne Alves Silva Martins Viana

ORCID: https://orcid.org/0000-0001-8230-9850 Faculdade de Minas, Brasil

E-mail: janynebhz@gmail.com

Patrícia Pereira da Silva

ORCID: https://orcid.org/0000-0003-3334-8233 Faculdade de Minas, Brasil

E-mail: patriciaps1988@yahoo.com.br

Gleisy Kelly Neves Gonçalves

ORCID: https://orcid.org/0000-0001-6007-9708 Faculdade de Minas, Brasil

E-mail: goncalvesgk@gmail.com

\begin{abstract}
Resumo
Introdução: A dengue é uma doença de notificação compulsória e uma ameaça à saúde populacional. Como principal estratégia para sua prevenção e controle está a educação em saúde e participação social. Objetivo: Promover a educação em saúde como estratégia de conscientização e prevenção da dengue. Metodologia: É um estudo de abordagem quali-quantitativa de caráter exploratório. Nesse estudo, utilizamos atividades educativas em saúde com crianças do ensino fundamental em uma escola estadual localizada em região com altos índices da doença na região nordeste de Belo Horizonte. A eficácia das atividades educativas foi avaliada através de questionários pré e pós intervenção. Resultados: Os resultados pós-teste mostraram um aumento considerável de assertividade das questões em mais de 50\% dos participantes, reforçando o êxito das intervenções. Discussão: Realizar uma educação continuada de forma criativa, com o uso de metodologias ativas/lúdicas no ambiente escolar, melhora a absorção e disseminação do conteúdo pelas crianças, elevando assim, a eficácia no combate à dengue. Conclusão: O estudo atingiu o público infantil de forma lúdica, com eficácia na promoção de conhecimentos e tal estratégia revela ser importante no diálogo e responsabilidade familiar no combate as doenças emergentes.
\end{abstract}

Palavras-chave: Dengue; Crianças; Educação em saúde.

\section{Abstract}

Introduction: Dengue is a disease with compulsory notification and a threat to population health. The main strategy for its prevention and control is education and social participation. Objective: To promote health education as a strategy for awareness and prevention of dengue. Methodology: It is an exploratory quali-quantitative approach study. 
In this study, we used health educational activities with elementary school children in a state school located in a region with high rates of the disease in Belo Horizonte (northeast region). The effectiveness of educational activities was assessed through using pre- and post-intervention questionnaires. Results: The post-test results showed a considerable increase in the assertiveness of the questions in more than $50 \%$ of the participants, reinforcing the success of the interventions. Discussion: Conducting continuing education in a creative way, using dynamic methodologies in the school environment, improves the absorption and dissemination of content by children, so increasing efficiency in combating dengue. Conclusion: The study reached the child audience in a playful way, effectively promoting knowledge and such a strategy proves to be important in the dialogue and family responsibility in combating emerging diseases.

Keywords: Dengue; Children; Health education.

\section{Resumen}

Introducción: El dengue es una enfermedad de notificación obligatoria y una amenaza para la salud de la población. La principal estrategia para su prevención y control es la educación y la participación social. Objetivo: Promover la educación sanitaria como estrategia para sensibilizar y prevenir el dengue. Metodología: Es un estudio de un enfoque exploratorio cualitativo-cuantitativa. En este estudio, utilizamos actividades educativas en salud con niños de escuela primaria en una escuela estatal ubicada en una región con altas tasas de la enfermedad en Belo Horizonte (región noreste). La eficacia de las actividades educativas se evaluó mediante cuestionarios previos y posteriores a la intervención. Resultados: Los resultados posteriores a la prueba mostraron un aumento considerable de la porcentaje de las preguntas correctas en más del 50\% de los participantes, reforzando el éxito de las intervenciones. Discusión: Llevar a cabo una educación continua de forma creativa, con el uso de metodologías activas/lúdicas en el entorno escolar, mejora la absorción y difusión de contenidos por parte de los niños, aumentando así la eficacia en la lucha contra el dengue. Conclusión: El estudio llegó al público del niño de una manera lúdica, promoviendo eficazmente el conocimiento y esa estrategia demuestra ser importante en el diálogo y la responsabilidad familiar en la lucha contra las enfermedades emergentes.

Palabras clave: Dengue; Niños; Educación para la salud.

\section{Introdução}

A dengue é uma doença de notificação compulsório e uma ameaça à saúde da população no mundo, transmitido mais comumente pelo vetor Aedes Aegypti. O impacto financeiro à saúde mundial pode ultrapassar 8 bilhões de dólares por ano. Além disso, mais de 390 milhões de pessoas foram infectadas pela arbovirose, conforme estudo realizado em 100 países (Da Silva et al., 2019; Nguyen-Tien et al., 2019).

Nos últimos 50 anos, juntamente com o crescimento populacional, a dengue aumentou cerca de 30 vezes sua incidência (Da Silva et al., 2019). Esse aumento refere-se à negligência no combate à dengue e banalização da doença. Criar programas e campanhas para a prevenção da dengue, visto que a erradicação da doença é ineficaz, devido a sua rápida proliferação, não é um método suficiente de controle sem o engajamento comunitário. Diversos estudos demonstram que mesmo sendo um desafio incansável, a educação e participação social para a prevenção da dengue é a melhor forma de alcançar êxito no controle do vetor (Da Silva et al., 2019; Kuramaran et al., 2018; Ledogar et al., 2017; Nguyen-Tien et al., 2019; Souza et al., 2018).

A aderência de adultos em programas educativos é muito baixa. A falta de interesse na participação de projetos preventivos e cuidados com a saúde é lamentável (Ledogar et al., 2017). Para atingir essa população alvo é necessário um grande esforço. Uma forma eficaz para alcançar esse objetivo é a educação infantil. Além de promover um aprendizado para uma vida toda, a criança é uma ponte que leva o conhecimento que detém para os adultos que a cercam. A mesma se enquadra como fonte de disseminação do conhecimento, e logo, serão cidadãos ativos na promoção da saúde (Alves et al., 2017; Vieira et al., 2017).

Educação e saúde possuem uma relação de interdependência e são extremamente importantes para evoluir ou regredir a qualidade de vida da população. Quando esses fatores trabalham em conjunto, alinhando práticas pedagógicas e saúde, ocorre a promoção da saúde; capacitando as pessoas em unidades escolares com cuidados integrais em saúde (Alves et al., 2017; Nicácio et al., 2017). Com o intuito de propagar a promoção da saúde, surgiu o Programa de Saúde na Escola (PSE) em 2007, 
com o objetivo de instruir crianças, adolescentes, jovens e adultos a cuidar de sua saúde, conscientizando e prevenindo diversos agravos a partir de brincadeiras e atividades escolares (Monzani et al., 2018; Souza et al., 2018).

Realizar ações educativas nas escolas, em especial no ensino fundamental, demonstra ser um método de aprendizagem muito eficaz. Apresentar o conteúdo de forma lúdica, com metodologias ativas para as crianças, proporciona uma absorção maior do conhecimento (Buchinger \& Hounsell, 2015; Monzani et al., 2018; Nicácio et al., 2017; Radhika et al., 2019; Vieira et al., 2017). Ações educativas de promoção à saúde nesta fase escolar, é um atalho para ampliar a disseminação do conhecimento sobre prevenção e controle do mosquito da dengue (Nicácio et al., 2017).

Com base nas considerações explicitadas, a escola é um ambiente favorável para realização de ações de cunho educativo voltado para a promoção da saúde. O presente estudo desenvolveu uma intervenção de educação em saúde com alunos do ensino fundamental, objetivando transmitir conhecimento sobre a tônica da doença dengue, enfatizando: sinais e sintomas, características da arbovirose, controle do vetor e barreiras físicas para a proteção do mosquito da dengue.

\section{Metodologia}

Estudo de abordagem quali-quantitativa de caráter exploratório realizado em uma escola estadual, localizada na Região Nordeste de Belo Horizonte. O estudo utilizou, de forma lúdica, estratégias de metodologias ativas com a temática da dengue para crianças do ensino fundamental.

A escolha do local de intervenção foi baseada em dados epidemiológicos. Para analisar os casos confirmados de dengue (CID-10 A90) no primeiro trimestre de 2019, foi realizado uma busca no DATASUS-Ministério da Saúde, Gerência de Vigilância Epidemiológica (GVIGE); Sistema de Notificação de Agravo e Notificação (SINAN); Diretoria de Promoção à Saúde e Vigilância Epidemiológica (DPSV); Secretaria Municipal de Saúde (SMS); Prefeitura de Belo Horizonte (PBH) e a Central de Zoonose da Região Nordeste, com o objetivo de identificar a região com maior incidência de dengue.

Os critérios usados para escolha da população infantil pesquisada foram faixa etária e estudarem em região mais acometida pela doença no município de Belo Horizonte no ano de 2019. As atividades de pesquisa e intervenção foram realizadas com todos os alunos do turno da manhã, compreendendo alunos de 7 a 10 anos de idade, com um total de 164 (cento e sessenta e quatro) participantes.

Buscou-se neste projeto, reduzir riscos e promover diversos benefícios na intervenção proposta para os participantes. Para isso, utilizou-se um aprendizado metodológico infantil de forma lúdica com atividades educativas, gincanas e brindes para ampliar a motivação das crianças. O trabalho seguiu as orientações expressas na Resolução do Conselho Nacional de Saúde 466/2012, que trata de pesquisas com seres humanos. Assim, foram assinados os Termos de Assentimento Livre e Esclarecido (TALE) pelas crianças e os Termos de Consentimento Livre e Esclarecido (TCLE) pelos pais, e submetido ao Comitê de Ética e Pesquisa (CEP) da Faculdade de Minas-FAMINAS-BH, obtendo anuência com o Certificado de Apresentação para Apreciação Ética (CAAE) de número 13119119.8.0000.5105.

O processo de pesquisa foi realizado em duas etapas que consistiram na aplicação de um pré-teste e um pós-teste para conhecimento dos níveis de entendimento dos alunos acerca do tema dengue. Ambos os testes possuíam as mesmas perguntas e grau de dificuldade. Já as intervenções, foram realizadas entre o período do pré e pós teste, consistindo em atividades semanais para os alunos e informalmente chamadas de "para casa", pois, se tratavam de atividades a serem realizadas em casa junto com os familiares. Essas atividades foram disponibilizadas pela secretaria municipal de saúde de Belo Horizonte. Foram utilizados dois folders (panfletos) que abordavam sobre aspectos importantes da dengue como sintomas, vetor e medidas de prevenção (Prefeitura de Belo Horizonte, 2016).

Além disso, uma gincana pedagógica foi realizada na escola com todos os sujeitos da pesquisa e organizada pelos pesquisadores deste estudo (Figura 1 e Quadro 1). A gincana seguiu etapas conforme descrito na figura abaixo: 
Figura 1 - Organograma com o fluxo da ação educativa.

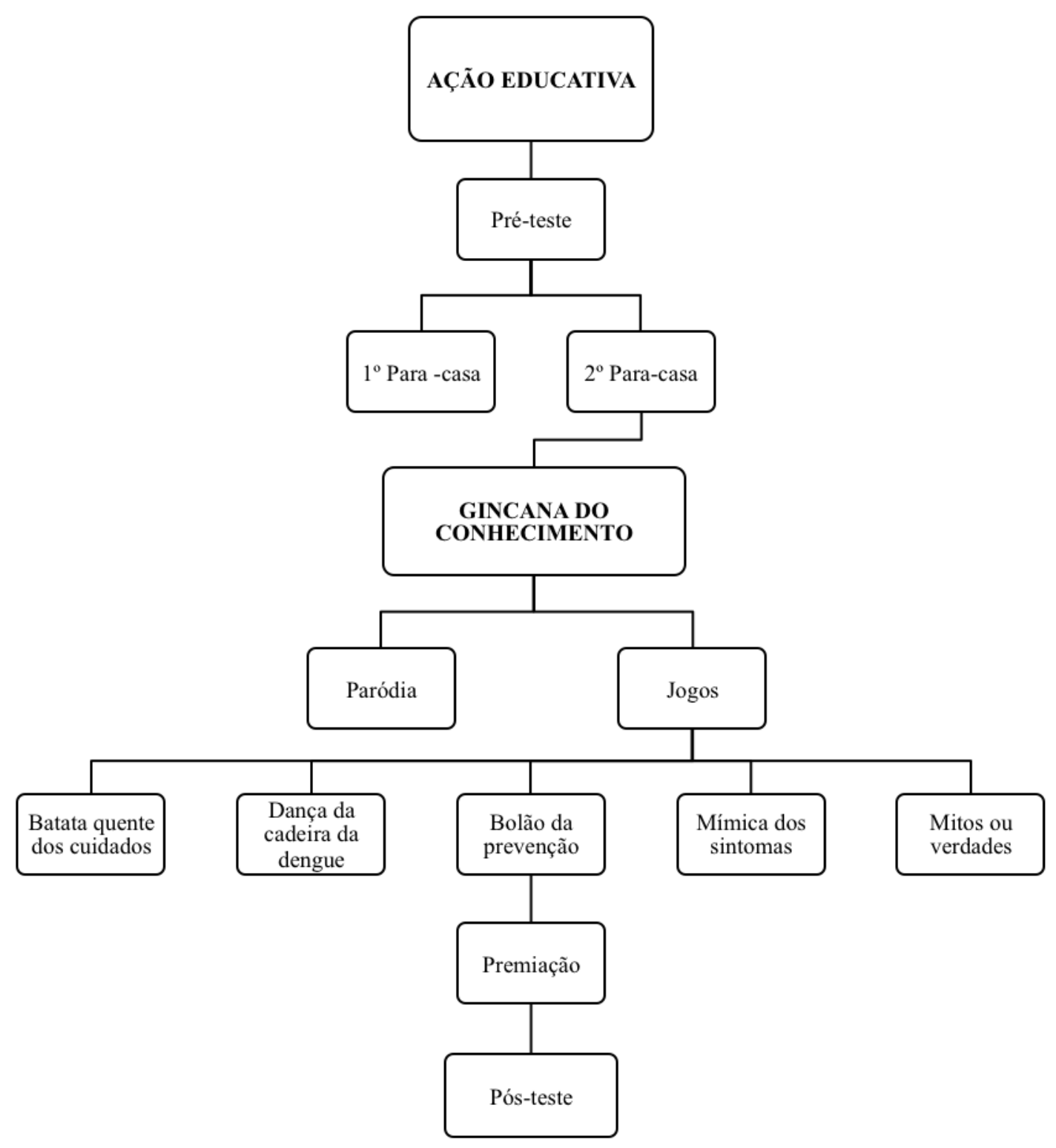

Fonte: Autores. 
Quadro 1 - Jogos realizados na gincana do conhecimento sobre dengue.

\begin{tabular}{|c|c|}
\hline JOGOS & CARACTERÍSTICAS \\
\hline Batata quente dos cuidados & $\begin{array}{l}\text { Em círculo, cada jogador deve passar a bola para o que } \\
\text { está a sua direita. Enquanto a bola circula, todos } \\
\text { cantam, a qualquer momento um jogador que está } \\
\text { vendado pode gritar: "Queimou!". Quem estiver com a } \\
\text { bola nas mãos nesse instante irá dizer um cuidado } \\
\text { necessário que se deve ter para prevenção da dengue. } \\
\text { Assim, quem não souber ou errar a resposta será } \\
\text { eliminado e o jogo continua até restar apenas um time } \\
\text { vencedor. Observação: Não foi aceito como resposta } \\
\text { correta cuidados repetidos. }\end{array}$ \\
\hline Dança das cadeiras da dengue & $\begin{array}{l}\text { Em forma de círculo cadeiras são posicionadas e uma } \\
\text { música "Se liga galerinha" tocada. No momento que a } \\
\text { música for pausada, os participantes devem assentar em } \\
\text { algum lugar. Sempre haverá uma cadeira a menos em } \\
\text { relação a quantidade de jogadores e aquele que não } \\
\text { conseguir um acento é eliminado. O último que restar } \\
\text { será o vencedor. }\end{array}$ \\
\hline Bolão da prevenção & $\begin{array}{l}\text { Dois representantes de cada time formam uma roda e } \\
\text { com uma bola em mãos cada um cita uma forma de } \\
\text { prevenir a dengue. Após dizerem um método de } \\
\text { prevenção, o jogador passa a bola para outro jogador de } \\
\text { sua escolha que também terá que dizer uma forma de } \\
\text { prevenir a doença e, assim, sucessivamente até restar } \\
\text { apenas um vencedor, ou maiores representantes de um } \\
\text { determinado time. }\end{array}$ \\
\hline Mímica dos sintomas & $\begin{array}{l}\text { Um jogador do time foi escolhido para realizar a } \\
\text { mímica (relacionada a um sintoma da dengue) e o } \\
\text { restante do grupo tem } 60 \text { segundos para tentar } \\
\text { adivinhar. Assim que tempo acabar o time deverá ter a } \\
\text { resposta certa, caso contrário, a equipe não ganha o } \\
\text { ponto e o time adversário tem a chance de adivinhar } \\
\text { qual sintoma que estava sendo apresentado. }\end{array}$ \\
\hline Mímica dos sintomas & $\begin{array}{l}\text { Um jogador do time foi escolhido para realizar a } \\
\text { mímica (relacionada a um sintoma da dengue) e o } \\
\text { restante do grupo tem } 60 \text { segundos para tentar } \\
\text { adivinhar. Assim que tempo acabar o time deverá ter a } \\
\text { resposta certa, caso contrário, a equipe não ganha o } \\
\text { ponto e o time adversário tem a chance de adivinhar } \\
\text { qual sintoma que estava sendo apresentado. }\end{array}$ \\
\hline Mito ou verdade & $\begin{array}{l}\text { Em uma parede foi fixado duas faixas com as palavras } \\
\text { "mito" à esquerda e "verdade" à direita, no qual os } \\
\text { jogadores de cada time deveram se posicionar para o } \\
\text { lado de uma das faixas respondendo uma pergunta } \\
\text { escolhida por nós. }\end{array}$ \\
\hline
\end{tabular}


O conceito de metodologias ativas e de educação em saúde foram considerados tanto para a construção das atividades, bem como para a análise do estudo. Nesta abordagem, os autores utilizaram o marco teórico e etapas, ambos sugeridos por Minayo (2012) para o estudo qualitativo. Para tanto, obtiveram uma análise prévia do conhecimento dos participantes da pesquisa acerca do tema (pré teste) para preparar as metodologias de educação em saúde adequadas para o público e tipo de erros observados. Foram elaboradas hipóteses que contribuíram para a construção das gincanas e, com tal estratégia foram obtidos resultados através do pós teste. Tais resultados, foram avaliados quantitativamente após serem agrupados por categorias de perguntas e níveis de dificuldade. A organização dos dados foi feita apresentando o percentual de erros e acertos nos dois momentos: antes e após a intervenção. Para comparar as médias entre os grupos no pré e pós teste, utilizamos o teste t de student que avalia se há diferença significativa entre as médias dos grupos. Os dados foram avaliados pelo software Prism 6 (1).

\section{Resultados}

Com os resultados obtidos nas análises dos testes, evidenciamos que ações voltadas para educação em saúde para a população infantil contribuem para o melhor conhecimento do tema, pelo fato da criança ser um potente ouvinte e disseminador de conhecimento em sua família, tornando-se então, público alvo para conscientização e um melhor controle epidemiológico.

Após contato e dados da secretaria de saúde e epidemiologia de Belo Horizonte, a terceira regional mais afetada com casos confirmados de dengue foi a região Nordeste, totalizando 86 casos entre janeiro e março de 2019.

O pré teste aplicado anteriormente a intervenção, continha 8 (oito) questões relativas à dengue, com o objetivo de avaliar o nível de conhecimento dos alunos sobre a temática e quais seriam os pontos de maior dificuldade, os quais seriam discutidos no momento da intervenção. O pré teste evidenciou que os alunos não possuíam conhecimento prévio de alguns elementos importantes sobre dengue, como representado na Figura 2. Os alunos demonstraram desconhecimento sobre a existência de uma vacina ( $93 \%$ de erros), as formas de prevenção ( $80 \%$ de erros) e por último, não souberam responder corretamente sobre o modo de transmissão da dengue (60\% de erros). 
Figura 2 - Representativo de acertos e erros das questões relativas a dengue no pré teste.

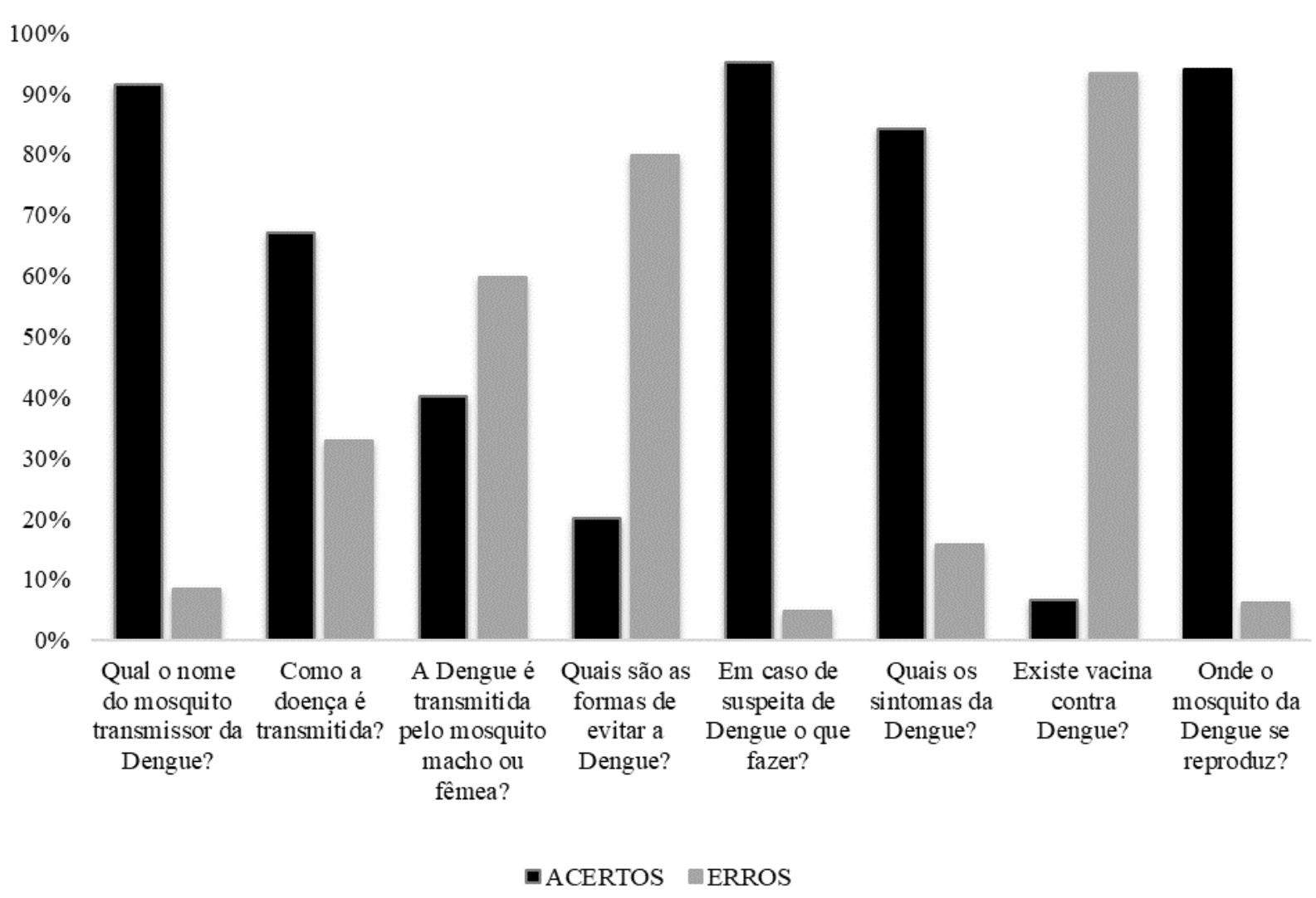

Fonte: Autores (2020).

Cada questão do teste aplicado aos alunos continha uma classificação do grau de dificuldade, sendo de nível fácil, médio ou difícil. Segundo Buchinger \& Hounsel (2015) essa é uma estratégia anti-chute que foi inspirada no jogo Sherlock dengue. Ou seja, a estratégia induzia o participante a refletir sobre cada alternativa, apresentando informações assertivas, justificadas, mas, misturadas a informações incorretas em uma proporção balanceada, dificultando a escolha aleatória das alternativas.

Na Figura 3, a maioria dos alunos assinalaram as questões como fáceis, mesmo aquelas que não obtiveram acertos. A maioria dos alunos classificaram todas as questões como fáceis, oscilando entre (57\% a 90\%) do total da amostra. 
Figura 3 - Percepção dos alunos quanto ao grau de dificuldade das questões no pré teste.

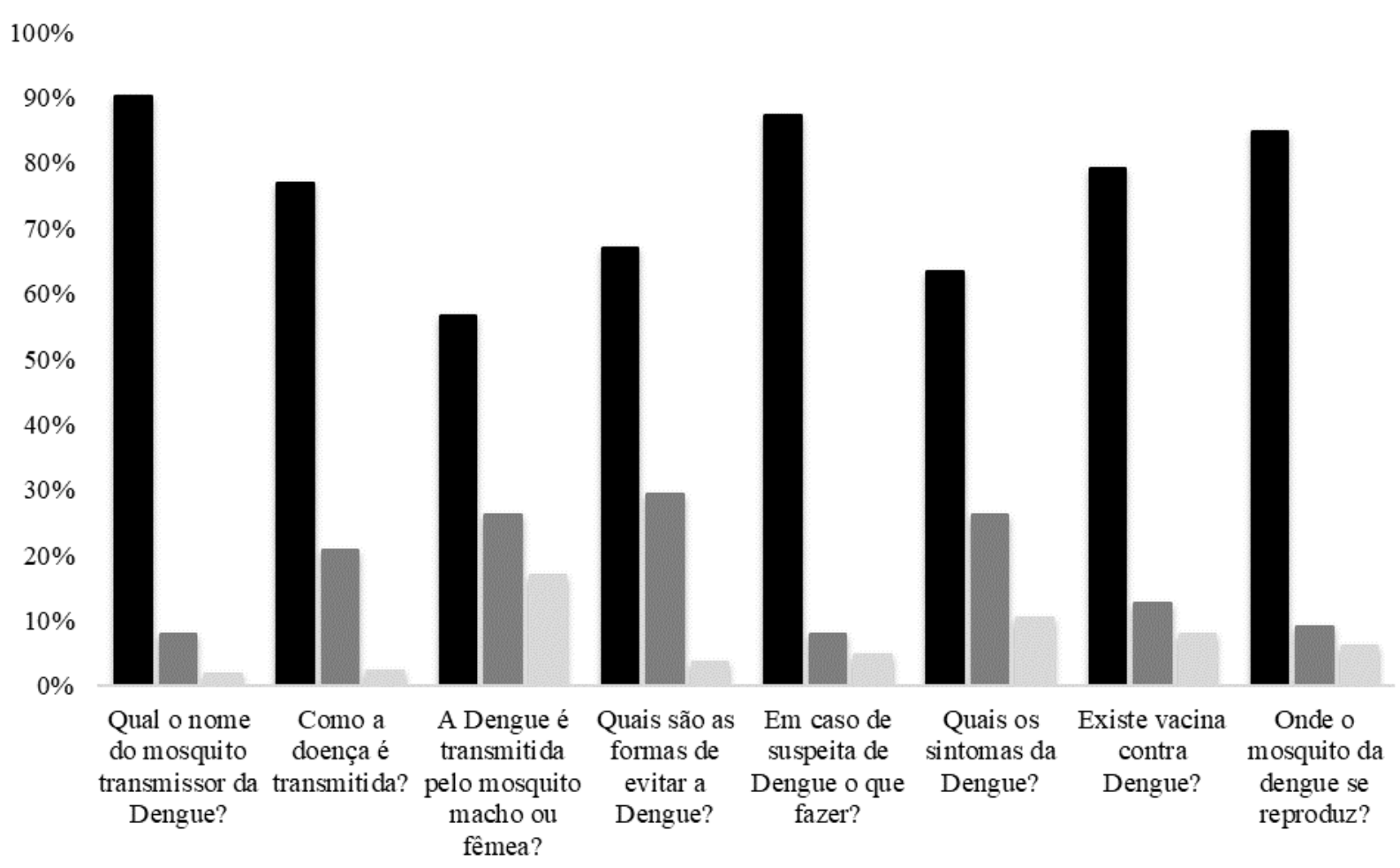

-FÁCIL MÉDIO DIFÍCIL

Fonte: Autores (2020).

Ao relacionar as Figuras 2 e 3, observamos que as questões com maior porcentagem de acertos (5, 8, 1, 6 e 2 respectivamente), tiveram uma relação compatível ao nível de complexidade de cada questão estipulada pelos alunos. $\mathrm{O}$ grau de dificuldade dessas questões, foram assinalados como fácil, sendo assim, o número de acertos versus o grau de dificuldade foi equivalente, mostrando que realmente as questões eram mais fáceis e eles saberiam responder corretamente. Em contrapartida, ao comparar as questões com maior percentual de erros (7, 4, e 3 de modo respectivo), a grande maioria dos estudantes assinalaram que essas questões teriam um nível de dificuldade fácil, porém a taxa de erros foi significativa. Um exemplo é notado pela questão de número 7 (sete), com (93\%) de erros, sendo que, (79\%) dos alunos assinalaram que a pergunta seria fácil, e somente (13\%) assinalaram de nível médio e de difícil (5\%) dos estudantes. Portanto, o número de acertos versus o grau de dificuldade demonstra contradição dos sujeitos da pesquisa.

Um falso conhecimento sobre a temática poderia ser a causa de tal confusão nos alunos, fazendo com que eles achassem a pergunta compreensível, porém não saberiam a resposta exata. Outro fator a ser avaliado foi que na faixa etária de 7 a 11 anos de idade, as crianças passam pelo estágio do operatório concreto, em que objetiva vencer seu adversário durante competições. A fim de demonstrar superioridade diante dos colegas, alguns alunos falaram em voz alta durante a realização do pré teste, “ah, essa está fácil”. Neste primeiro momento, não se pode garantir que a questão de nível fácil pela percepção dos alunos seria a que mais obteria respostas assertivas.

Dentro da perspectiva de promover a educação em saúde com crianças, realizamos uma intervenção denominada gincana do conhecimento. Proporcionar o conhecimento para os alunos de forma lúdica é uma meta a ser alcançada. Durante uma brincadeira, a criança aumenta sua capacidade de aprendizado, de forma dinâmica, conseguindo compreender e expressar por meio de variadas linguagens. Devido ao fato de imaginar e realizar um ato prazeroso, a fixação ocorre de maneira mais 
simples e a educação em saúde com crianças deve sempre envolver o que elas gostam de fazer, favorecendo um melhor aprendizado.

A Gincana iniciou-se com uma paródia infantil, "Se liga galerinha" de autoria dos pesquisadores com adaptação da música Vem cá sacudir (Ferrão, E., 2018). A música é uma importante ferramenta para chamar a atenção das crianças. Por meio dela, foi possível uma maior aproximação de forma divertida e eficaz. Em seguida, foram realizados os jogos (Tabela 1), com cinco brincadeiras, em que as questões de maior percentil de erros do teste foram trabalhadas neste momento.

Os participantes foram divididos em times e cada um elegia um representante para realizar o jogo. Cada um possuía uma quantidade de pontos e com a somatória final nomeamos a turma campeã, ganhadora da medalha. Desde o início da intervenção foi comunicado que os participantes teriam que estudar o conteúdo sugerido.

Após uma semana da gincana do conhecimento, o mesmo teste aplicado inicialmente aos alunos foi repetido pelos professores da instituição (pós teste). Com os resultados do pós teste (Figura 4) pode-se afirmar que a gincana foi eficaz promovendo a retenção de conhecimento. A maioria dos alunos conseguiu compreender os pontos mais frágeis identificados no pré teste.

Figura 4 - Representativo de acertos e erros das questões relativas a dengue no pós teste.

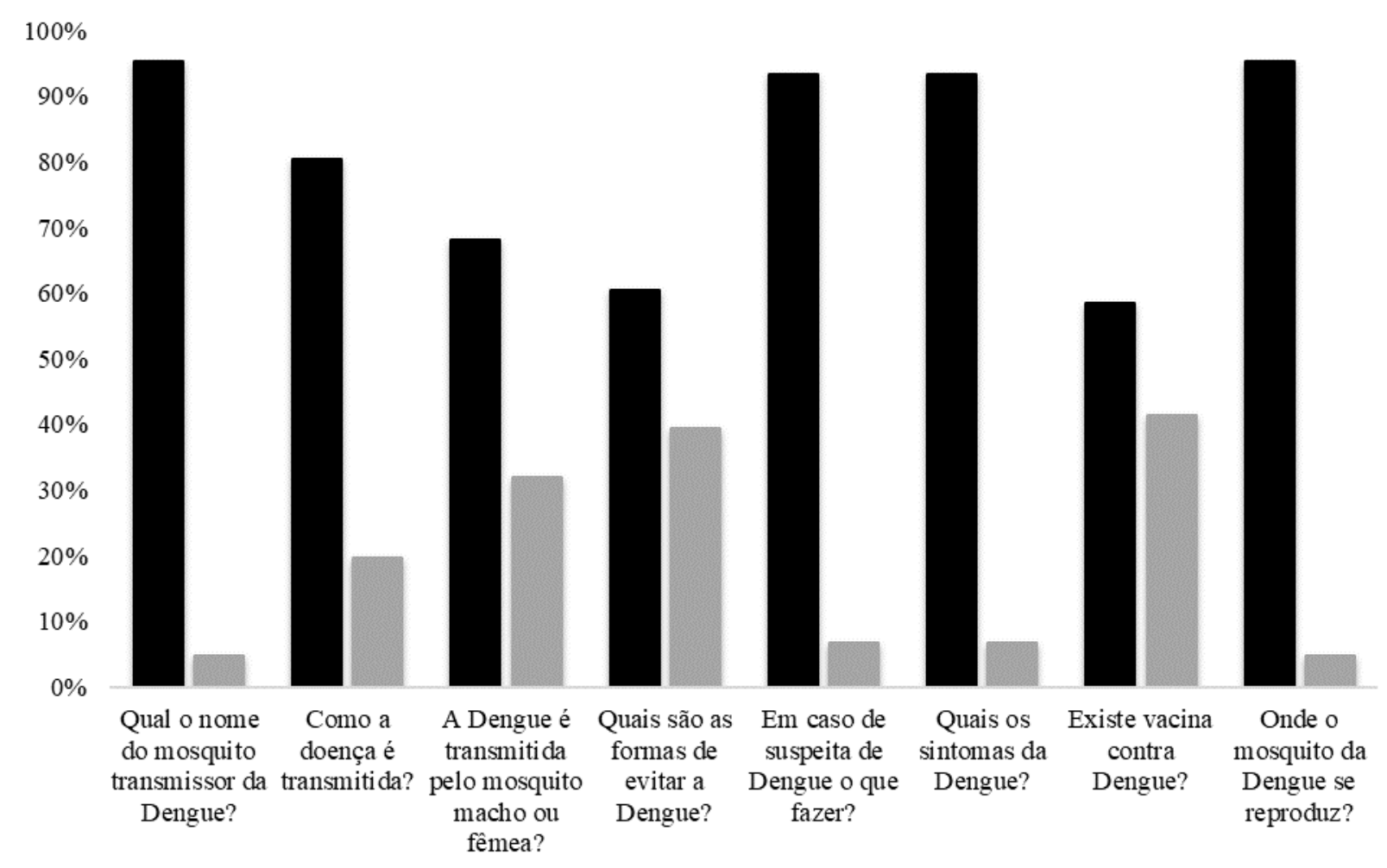

- ACERTOS ERROS

Fonte: Autores (2020).

A elevação do número de acertos nas questões de maior dificuldade, obteve um rendimento de mais de (50\%). Ao analisar esse rendimento entre o pré e pós teste, apresentamos os seguintes resultados, respectivamente: questão de número 7 (sete) obteve (7\% e após 59\%) de acertos; questão de número 4 (quatro) alcançou (20\% e após 61\%) de acertos; e por último a questão de número 3 (três) com (40\% e após 68\%) de respostas de assertivas. Quanto a classificação do nível de dificuldade de 
cada questão assinalada pelos alunos no pós-teste, em sua maioria, classificou-as como fáceis, porém desta vez, todas as questões tiveram um aumento positivo e ultrapassaram o percentil de erros.

\section{Discussão}

As análises dos testes evidenciaram que as ações voltadas para a educação em saúde por meio da gincana do conhecimento e atividades sobre o tema, contribuíram positivamente para o aprendizado da população alvo e, também, foi possível analisar as questões de maior dificuldade dos alunos tendo em vista os erros obtidos no pré-teste. A efetividade das ações é demonstrada pelo fato de a quantidade de questões assertivas serem maior no pós teste comparada ao pré-teste. O aumento do número de acertos das questões de maior dificuldade (existência de uma vacina, formas de prevenção e modo de transmissão da dengue, respectivamente) foi comprovada pelo maior rendimento (mais de 50\%) no pós teste, demonstrando que as informações foram bem compreendidas pelos participantes.

A dengue é um grave problema de saúde pública que causa a morte de centenas de pessoas no país todos os anos. Segundo dados do governo federal, em Minas Gerais 8 pessoas morreram e 30.328 contraíram a doença no ano de 2018 . O Ministério da Saúde divulgou ainda que Minas Gerais é o estado com maior coeficiente de incidência de dengue no Brasil, com 483.545 casos em 2019, o que representa 2.284 contaminados para cada 100 mil habitantes. Ao final do ano de 2019 , até o dia 30 de dezembro, foram contabilizados um total de 172 óbitos e 483.545 casos em investigação (Ministério da Saúde, 2019; Secretária de Vigilância em Saúde, 2020).

Segundo dados do Governo Federal, o Brasil gasta em média 1.5 bilhão de reais para o combate ao vetor. Minas Gerais está entre os 5 estados que apresenta os maiores gastos com tratamento dessa arbovirose no país (Teich et al., 2017). Em 2019 o Ministério da Saúde antecipou a campanha de combate ao vetor da dengue que visava mobilizar governos estaduais e municipais para este feito. O repasse de verbas teve um orçamento em torno de 1,8 bilhão de reais (Ministério da Saúde, 2019).

É importante ressaltar a necessidade de evidenciar para a população que a dengue é uma doença de suscetibilidade universal, e que, em pessoas que já contraíram a doença mais de uma vez ou possuem o sistema imunológico menos resistente, pode apresentar manifestações nas formas graves, o que aumenta mais as chances de causarem complicações (agudas/crônicas) e levar ao óbito. Estudos recentes indicam que 2,5 bilhões de pessoas no mundo apresentam uma maior suscetibilidade a contraírem a doença da dengue por viverem em áreas de risco de transmissão do vírus, culminando em milhões de infectados por ano (Arantes \& Pereira, 2017; Nguyen-Tien et al., 2019; Pereira \& Lemes, 2018).

A falta de atuação ativa em programas de serviços de saúde é vista principalmente em países subdesenvolvidos. No que tange o aumento do número de casos a cada ano refere-se à negligência no combate da dengue. Nas literaturas, o que mais sobressai como ato de banalização no controle de disseminação do mosquito, é a falta de participação e conscientização das comunidades; sem a participação ativa da população o controle do vetor é ineficiente. Aderir um bom engajamento comunitário é uma tarefa difícil, porém, cada vez mais, é promovido na prática de saúde preventiva, sendo um processo contínuo de diálogo com a sociedade (Da Silva et al., 2019; Kumaran et al., 2018; Ledogar et al., 2017; Nguyen-Tien et al., 2019).

Em um estudo realizado no México e Nicarágua por Ledogar et al. (2017) mostra que várias organizações não aderem e dificilmente envolvem em práticas de prevenção da dengue e os proprietários de estabelecimentos de comércio como lojas, fábricas, revendedores de sucata, são incomunicáveis e incompreensíveis. A educação social é um ato complexo e de difícil aderência com adultos, por esse motivo, a promoção da saúde deve ser realizada durante a infância, adaptado no contexto local, para que o processo de participação ativa na prevenção da dengue e conscientização de responsabilidade individual seja enraizada até a fase adulta. Em contrapartida, para Souza et al. (2018) a responsabilidade social sobre a reprodução do 
mosquito já está implantada em cada indivíduo, quando se culpa o outro, normalmente o vizinho, por possíveis focos de criação de dengue em sua residência. Sendo assim, o que falha, é o entendimento da real educação social.

No Brasil, existem diversos locais como lotes abandonados, acúmulo de lixo e construções públicas paradas com grande quantidade de resíduos, que somados a uma coleta de resíduos inadequada pode ocasionar focos de proliferação do Aedes Aegypti. As barreiras para a compreensão e comprometimento das comunidades em programas de prevenção da dengue, incluem: falta de interesse e a atitude da comunidade e/ou governo; dificuldade de comunicação com a população durante os programas de prevenção; poucas aplicações de políticas relacionadas e orçamento limitado para esse tipo de ação (NguyenTien et al., 2019).

Mesmo com diversos esforços para a prevenção contra a disseminação do mosquito, existe uma constante banalização da doença e desconhecimento de todas suas formas de prevenção. Educar a população continua sendo um grande desafio para enfrentar a problemática, principalmente em países com baixa escolaridade. As populações que possuem menos de 6 (seis) anos de escolaridade, tem 10 (dez) vezes mais chances de não realizar uma prevenção adequada, por possuir frágil conhecimento sobre essas medidas (Kumaran et al., 2018).

A conscientização e responsabilização das comunidades são essenciais para que haja a diminuição da doença (Vieira et al., 2017). Para isso ocorrer é preciso intensificar as ações educativas. A Atenção Primária à Saúde (APS) deve proporcionar medidas socioeducativas, através de intervenções que ultrapasse as barreiras físicas da unidade básica de saúde. Em 2007, foi implantado no Brasil o Programa Saúde na Escola (PSE), uma política intersetorial entre o Ministério da Saúde e o Ministério da Educação, com finalidade de promover práticas de promoção e prevenção de agravos; promovem diversas intervenções educativas que são realizadas pela integração da escola e atenção básica de saúde (Da Silva et al., 2019; Monzani et al., 2018; Secretária de Vigilância em Saúde, 2020).

A pedagogia tradicional é uma prática metodológica com aulas expositivas, sem uma interdisciplinaridade e sem estar sincronizada a realidade do aluno. Restringe o professor como o transmissor e o aluno como receptor - o primeiro como único detentor de conhecimento e com direito à palavra, e o segundo, apenas com direito de receber e compreender o que foi passado. Esse contexto atrapalha o aprendizado da criança. É importante o envolvimento do aluno com a teoria, prática e interação com o professor em sala de aula e demais ações educativas. Com essas medidas, a criança desenvolve a fixação do assunto e posteriormente divulga o conhecimento de forma segura e correta (Paiva et al., 2019; Pereira \& Lemes, 2018).

Em todas atividades realizadas na intervenção educativa do nosso estudo, foi priorizado o processo interativo com as crianças, visando extinguir o formato tradicional transmissor-receptor do ensino, propiciando a compreensão dos processos sociais locais no contexto da dengue. Houve interação também com a entrega do "para casa" para ser realizado em casa com seus familiares. As crianças são disseminadoras do conhecimento e poder compartilhar as suas experiências com outras pessoas amplia as chances de prevenção e eliminação de focos da dengue por meio da conscientização.

O modelo pedagógico tradicional vem passando por constantes transformações. Para ajudar nesse remodelamento, o ensino vem trazendo atividades lúdicas e metodologias ativas, colocando o aluno no centro da atividade, utilizando uma transmissão de conhecimento de forma horizontalizada e integral, trazendo pensamento universal e humanista dentro da sala de aula e promovendo o trabalho em equipe (Alves et al., 2017; Paiva et al., 2019).

Nas escolas, principalmente no ensino fundamental, as crianças estão em desenvolvimento cognitivo. É admirável que as instituições escolares agreguem seus alunos com conhecimento introdutório de saúde pública e integração social. Aplicando estas temáticas, a disseminação desse conhecimento por parte das crianças atingirá um público alvo importante, os adultos, que servirá como mais um atuante na prevenção da dengue (Monzani et al., 2018; Nicácio et al., 2017; Pereira \& Lemes, 2018).

Segundo Radhika et al. (2019) o nível de entendimento, conhecimento prévio e compreensão pode variar entre as escolas, em que a mesma atividade pode ter um impacto diferente para cada grupo de alunos, obtendo adesão e compreensão 
para uma escola e não sendo efetiva em outras. Dessa forma, a metodologia ativa/lúdicas deve ser bem adaptada no contexto local, atento sempre as variações socioculturais. Diante do exposto, Alves et al. (2017) demonstra em seu estudo, que se a criança participa de uma metodologia ativa, ela se torna mais atraída e participativa, conseguindo posteriormente disseminar informações para familiares, amigos e vizinhos, utilizando a transmissão verbal e/ou visual de informação, replicando a "brincadeira" em seu convívio social.

Foi baseado neste contexto que a gincana, paródias e jogos foram desenvolvidas. Assim, adaptações nessas atividades puderam deixar acessível e significativa para os participantes, permitindo maior elo e aprendizado.

Além das ações executadas pelos órgãos públicos, a comunidade acadêmica junto com seus orientadores, têm colaborado com ações educativas para a população, em particular com o público infantil, devido a efetividade das intervenções. Estudos apresentaram que diversas ações foram realizadas por meio de projetos de extensão, fornecida pelas instituições de nível superior, por pesquisadores e estudantes da área da saúde (Amorim et al., 2017; Nicácio et al., 2017; Soares et al., 2017; Vieira et al., 2017).

Algumas publicações relatam a experiência e importância de realizar ações educativas nas escolas, principalmente com crianças do ensino fundamental. Constata-se que é utilizado uma pedagogia horizontalizada, por meio de metodologia ativa. Para favorecer o processo de aprendizagem são empregadas atividades lúdicas, por estimular a imaginação das crianças, além de ser atrativo e divertido. Os estudos demonstram similaridade entre os métodos de ensino e aprendizado aplicados, com feedbacks positivos das intervenções. Os recursos utilizados foram: peça de teatro, teatro de fantoches, brincadeira, jogos educativos e paródia de músicas infantis. Apresentando o propósito de promover o conhecimento sobre forma de transmissão, sinais e sintomas, combate ao vetor e caso doente, procurar atendimento (Amorim et al., 2017; Nicácio et al., 2017; Soares et al., 2017; Vieira et al., 2017).

De acordo com Nicácio et al. (2017), uma intervenção educativa tem a finalidade de provocar uma modificação intencional, no local onde se trabalha um esquema terapêutico ou profilático. Alguns autores intervencionais no campo de combate à dengue através do público infantil, revelam que a ação educativa obteve um feedback positivo, após utilizar recursos que os auxiliaram a avaliar a efetividade da intervenção. Soares et al. (2017) informa que empregou um quiz para verificar o conhecimento absorvido. Buchinger \& Hounsell (2015) apontam ter aplicado uma avaliação antes e depois da intervenção, juntamente com um método para evitar o "chute", com escala de 0 a 10, investigando o grau de confiança nas respostas dos participantes.

A técnica do método anti-chute, que evita a escolha aleatória de qualquer alternativa sem antes refletir sobre ela, foi utilizada em nosso estudo através da classificação do grau de dificuldade e, foi uma ferramenta que possibilitou averiguar o quanto as crianças sabiam sobre o assunto. Em todas as questões, tanto no pré teste quanto no pós teste, os alunos assinalaram em sua maioria que todas as questões eram de nível fácil, mesmo aquelas que havia um alto índice de erros. Essa técnica mostra-se eficaz, pois se a criança assinala que a questão é fácil e erra, provavelmente seu conhecimento sobre o assunto está frágil e precisa ser reforçado. Nessa perspectiva, a gincana foi elaborada para reforçar o conteúdo das questões de grau de dificuldade de nível fácil que obteve maior porcentagem de erros, bem como outros erros de dificuldade maior.

Alguns jogos encontrados na literatura não visam a competitividade e colaboração como forma de aprendizado, já outros, é visto como uma alternativa de disseminação de conhecimento. Jogos alternativos auxiliam no processo de aprendizagem, aumentando o nível de conhecimento e assim melhoram a disseminação das informações durante o processo (Buchinger \& Housell, 2015).

Para gerar conscientização no combate à dengue na idade escolar, o Programa Saúde na Escola no início do ano letivo de 2019, mobilizou mais de 18 milhões de estudantes e familiares pela causa, percorrendo mais de 115 capitais brasileiras que eram prioridade no combate do vetor da dengue (Ministério da Saúde, 2016). 
As informações para o combate ao vetor devem fazer parte da educação de alunos de todas as idades. A orientação é fundamental, pois permite tomada de decisões e discussões em casa e vizinhança, reforçando sua responsabilidade no cenário social (Ministério da Saúde, 2016).

Existem alguns programas ativos para o combate ao vetor no país, mas o crescente número de casos determina a baixa efetividade desses programas (Sousa et al., 2018). Devido ao número crescente de casos, ações de prevenção precisam ser realizadas no meio escolar, pois crianças são transformadoras e comunicadoras, isso faz com que as informações sejam absorvidas de forma eficaz e rápida. Uma efetiva ação educativa contribui para a diminuição da incidência e redução dos casos de dengue, como palestras interativas em escolas, visando a deficiência de interação da gestão com essa parcela da população (Buchinger \& Housell, 2015; França et al., 2017).

Alguns dificultadores no combate à dengue também chamam atenção, como o fato de significativa parte da população conviver com criadouros do mosquito, residências fechadas/abandonadas e dificuldade de acesso dos Agentes Comunitários de Saúde (Cavalli et al., 2019). Considerando tal contexto é que a prática de ações educativas com crianças torna-se uma estratégia valiosa para promoção à saúde e conscientização social, pois estas desempenham um papel social importante no combate à dengue.

\section{Conclusão}

Por meio das atividades lúdicas desenvolvidas, houve uma modificação significante no processo de aprendizagem infantil, conforme observado nas mudanças de percentual dos erros e acertos. Os resultados evidenciaram a importância de realizar ações educativas com as crianças, atrelado a modificação do pensamento e conhecimento sobre o tema. Por meio da gincana do conhecimento, foi ampliado o nível do saber das crianças sobre a dengue, promovendo resultado positivo esperado com a intervenção.

Ao utilizarmos uma metodologia ativa, conseguimos ensinar aos alunos de forma lúdica sobre um tema de grande relevância para a saúde pública. A didática lúdica utilizada com as crianças foi eficiente para aperfeiçoar seus conhecimentos sobre práticas de prevenção e controle da dengue e facilidade na transmissão do conhecimento por parte dos integrantes da ação. Dessa maneira, confirmamos que a promoção em saúde com o público alvo baseadas em metodologias ativas é eficiente para o aprendizado e disseminação do conhecimento.

\section{Referências}

Alves, D., Cardoso, G., Miranda, M., \& Barbosa, M. (2017) Ação educativa no combate a dengue. Revista Magsul de Educação da Fronteira, 2(1), 456-459.

Arantes, K. M., \& Pereira, B. B. (2017) Levantamento, análise e seleção de indicadores ambientais e socioeconômicos como subsídio para o fortalecimento das estratégias de controle da dengue no município de Uberlândia-MG. Journal of Health and Biological Sciences. 5(1), 8694.

Amorim, J. S., Junior, R. G. C. S., \& Cordeiro, J. C. P. (2017) Ações educativas em saúde ambiental e humana: teatro de fantoches e dengue. EXTRAMUROS-Revista de Extensão da Univasf, 5(1), 137-142.

Bunchinger, D., \& Hounsell, M. (2015) O aprendizado através de um jogo colaborativo-competitivo contra dengue. In: Brazilian Symposium on Computers in Education (Simpósio Brasileiro de Informática na Educação-SBIE). p. 439.

Cavalli, F., Seben, J., Busato, M., Lutinski, J., \& Andrioli, D. (2019). Controlling the Vector Aedes Aegypti and Handling Dengue Fever Bearing Patients / Controle do Vetor Aedes Aegypti e Manejo dos Pacientes com Dengue. Revista de Pesquisa: Cuidado é Fundamental Online, 11(5), 1333-1339. doi:http://dx.doi.org/10.9789/2175-5361.2019.v11i5.1333-1339.

Da Silva, B., Porto, F. G., Marchionatti, A., Machado, R. dos S., Moraes, S. de, Schimidt, J. C., Oliveira, B., Mendes, N. H., Ribas, M. A., \& Carvalho, T. G. M. L. de. (2019). Evaluation about Dengue knowledge of children at school age. ABCS Health Sciences, 44(1). https://doi.org/10.7322/abcshs.v44i1.1068. 
Ferrão, E. (2018). Vem cá sacudir. Rio de Janeiro, RJ: 2018.

França, E. B., Lansky, S., Rego, M. A. S., Malta, D. C., França, J. S., Teixeira, R., Porto, D., Almeida, M. F., Souza, M. F. M., Szwarcwald, C. L., Mooney, M., Naghavi, M., \& Vasconcelos, A. M. N. (2017). Principais causas da mortalidade na infância no Brasil, em 1990 e 2015: estimativas do estudo de Carga Global de Doença. Revista Brasileira de Epidemiologia, 20(1), 46-60. https://doi.org/10.1590/19805497201700050005 .

Kumaran E., Doum D., Keo V., Sokha L., Sam B., Chan V., et al. (2018) Dengue knowledge, attitudes and practices and their impact on community-based vector control in rural Cambodia. PLoS Negl Trop Dis 12(2): e0006268. https://doi.org/10.1371/journal.pntd.0006268.

Ledogar, R. J., Hernández-Alvarez, C., Morrison, A. C. et al. (2017) When communities are really in control: ethical issues surrounding community mobilisation for dengue prevention in Mexico and Nicaragua. BMC Public Health 17, 410. https://doi.org/10.1186/s12889-0174305-9.

Minayo, M. C. S. (2012) Análise qualitativa: teoria, passos e fidedignidade. Ciência \& Saúde Coletiva, 17(3), 621-626. https://doi.org/10.1590/S1413-81232012000300007.

Ministério da saúde. (2007) Decreto $n^{\circ}$ 6.286, de 5 de dezembro de 2007. Institui o Programa Saúde na Escola - PSE, e dá outras providências. Brasília, 2007. http://www.planalto.gov.br/ccivil_03/_ato2007-2010/2007/decreto/d6286.htm.

Ministério da saúde. (2016) Crianças são fundamentais no combate ao mosquito Aedes Aegypti. Brasil. http://www.blog.saude.gov.br/index.php/combate-ao-aedes/50842-criancas-sao-fundamentais-no-combate-ao-mosquito-aedes-aegypti

Ministério da Saúde. (2019) Situação Epidemiológica/ Dados. Ministério da Saúde, Brasil. https://www.saude.gov.br/saude-de-az/dengue/situacao-epidemiologica-dados

Ministério da Saúde. (2019) Ministério da saúde lança campanha de combate ao Aedes aegypti. Brasil. https://www.saude.gov.br/noticias/agencia-saude/45788-ministerio-da-saude-lanca-campanha-de-combate-ao-aedes-aegypti-12-09-2019

Monzani, E. E., Santana, M. L. C. \& Franceschini, S. D. (2018) Projeto Agente Mirim contra Dengue com alunos do $1^{\circ}$ ao $5^{\circ}$ ano nas escolas municipais e particulares do município de Descalvado/SP. Boletim do Instituto de Saúde: BIS, p. 80-83.

Nicácio, L. A., Davim, R. M. B., Oliveira, M. B., Camboim, J. C. F., Medeiros, H. R. L. \& Oliveira, S. X. (2017) Intervenção educativa sobre o mosquito Aedes aegypti em escolares: possibilidade para a enfermagem no contexto escolar. Rev. enferm. UFPE on line, $3771-3777$. 10.5205/reuol.12834-30982-1-SM.1110201710 .

Nguyen-Tien, T., Probandari, A. \& Ahmad, R. A. (2019). Barriers to engaging communities in a dengue vector control program: an implementation research in an urban area in Hanoi City, Vietnam. The American journal of tropical medicine and hygiene, 100(4), 964-973.

Paiva, J. H. H. G. L., Barros, L. C. M., Cunha, S. F., Andrade, T. H. S. \& Castro, D. B. (2019). O Uso da Estratégia Gameficação na Educação Médica. Revista Brasileira de Educação Médica, 43(1), 147-156. https://doi.org/10.1590/1981-52712015v43n1rb20170140.

Pereira, C. M. \& Lemes, J. R. A. (2018) Medidas de educação e saúde na escola: prevenção contínua contra a dengue. Em Extensao, 17(1).

Prefeitura de Belo Horizonte. (2016). Perigo Aumentou Checklist [folder]. Prefeitura.pbh. https://prefeitura.pbh.gov.br/sites/default/files/estrutura-de-governo/saude/2018/publicacaoes-da-vigilancia-emsaude/folder_perigo_aumentou_check_list_2016.pdf.

Radhika, N., Gunathilaka, N., Udayanga, L., Kasturiratne, A., \& Abeyewickreme, W. (2019). Level of Awareness of Dengue Disease among School Children in Gampaha District, Sri Lanka, and Effect of School-Based Health Education Programmes on Improving Knowledge and Practices. BioMed research international, 2019, 3092073. https://doi.org/10.1155/2019/3092073.

Secretaria de Vigilância em Saúde. (2020) Boletim Epidemiológico de Monitoramento dos Casos de Arboviroses Urbanas Transmitidas Pelo Aedes. Ministério da Saúde, Brasília, 51(2). https://www.saude.gov.br/images/pdf/2020/janeiro/20/Boletim-epidemiologico-SVS-02-1-.pdf;

Soares, F., Gonçalves, A., Alvim, R., Mourão Júnior, C., \& Oliveira, C. (2017). Método educacional infantil na prevenção e combate à dengue, zika vírus e chikungunya. Extensão em Foco, 1(13). http://dx.doi.org/10.5380/ef.v1i13.46502.

Sousa, R. P., Rasella, D. \& Carepa-Sousa, J. (2018) Política econômica e saúde pública: equilíbrio fiscal e bem-estar da população. Saúde em Debate, 42, 172-182.

Souza, K. R., Santos, M. L. R., Guimarães, I. C. S., Ribeiro, G. de S. \& Silva, L. K. (2018). Saberes e práticas sobre controle do Aedes aegypti por diferentes sujeitos sociais na cidade de Salvador, Bahia, Brasil. Cadernos de Saúde Pública, 34(5), e00078017. https://dx.doi.org/10.1590/0102-311x00078017.

Teich, V., Arinelli, R. \& Fahham, L. (2017) Aedes aegypti e sociedade: o impacto econômico das arboviroses no Brasil. JBES: Brazilian Journal of Health Economics/Jornal Brasileiro de Economia da Saúde, 9(3). 
Research, Society and Development, v. 10, n. 1, e2110110864, 2021

(CC BY 4.0) | ISSN 2525-3409 | DOI: http://dx.doi.org/10.33448/rsd-v10i1.10864

Vieira, S. N. S., França, L. S., Lima, J. J. P., Souza, F. S. \& Cardim, S. Q. (2017) Educação em saúde e o combate à dengue: um relato de experiência. Rev. enferm. 2227-2230. 10.5205/reuol.9302-81402-1-RV.1105sup201730. 